\title{
Mortality rate and predictors of Stroke: A Meta-Analysis and Systematic Review
}

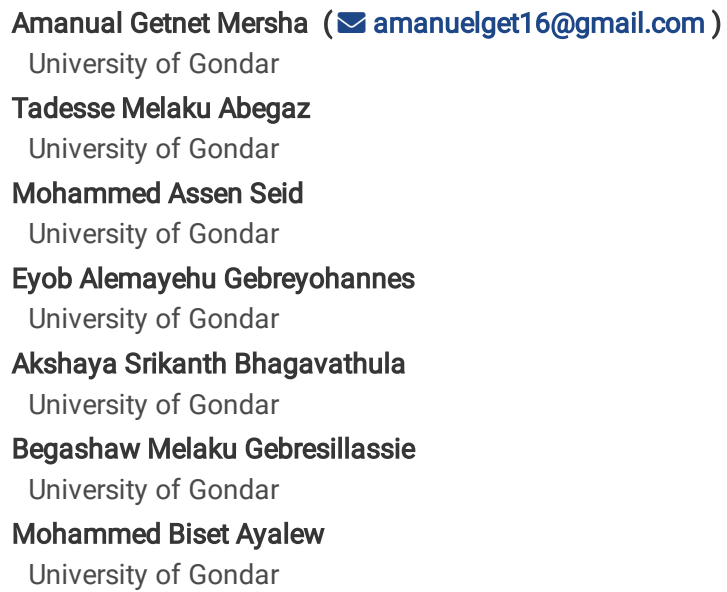




\section{Abstract}

Background Global data on stroke mortality remained to be sparse. In light of this, we aimed to conduct a Meta-analysis and systematic review of observational studies to estimate the mortality of stroke and to identify risk factors that predispose patients for stroke-related death.Methods This study was conducted based on the Meta-Analyses of Observational Studies in Epidemiology (MOOSE) guidelines. Overall mortality, in-hospital and 30- day mortality due to stroke were the primary outcome measures of the study. The meta-analysis was performed using Stata (Version 14, Stata Corp, College Station, Texas). Random-effect models were used for estimating pooled effects.Findings Overall, thirty two studies assessed overall mortality due to stroke. A total number of $2,885,126$ patients were recruited for the study. Pooled estimate indicated that the overall mortality of stroke was reported to be $20 \%$ (19\%-22\%). Whereas, the 30-day and In-hospital mortality were found to be 18\% (16\%-20\%) and 16\% (16\%-19\%), respectively. A subgroup analysis revealed that Africa registered the highest stroke-related death $29 \%$ (23\%-36\%). Hypertension was found to be an important risk factor for mortality secondary to stroke $61.9 \%$ (52.8\%-71.1\%).Conclusion Overall mortality of stroke was estimated to be twenty percent. The burden of stroke mortality was prominent in Africa region. Hypertension remained to be an independent risk factor for stroke mortality. Mortality of stroke can be minimized by establishing stroke centers that promptly deliver emergency management of stroke event.

\section{Background}

The American Heart Association (AHA)/American Stroke Association (ASA) expert consensus document defines "stroke" as a range of disorders including ischemic stroke (IS), silent central nervous system (CNS) infarction, intra-cerebral hemorrhage (ICH), silent cerebral hemorrhage, subarachnoid hemorrhage (SAH), cerebral venous thrombosis, and stroke not otherwise specified [1].According to the global burden of diseases (GBDs), stroke was the second most common cause of deaths (11.8\%) worldwide, next to ischemic heart disease (14.8\%) and the third most common cause of disability (4.5\%) [1-2]. Stroke produces substantial health and economic impact in the world [2-3]. IS remained the most common type of stroke in both developed and developing countries [4].In 2013, there were around 25.7 million stroke survivors in the world, of which $71 \%$ were with IS. The number of deaths from stroke and Disability Adjusted Life Years (DALYs) due to stroke were 6.5 million and 113 million, respectively. There were also 10.3 million new cases of stroke in the same year [2-3].

There are several risk factors for the occurrence of stroke and related mortalities. When ranking these risk factors to stroke by DALYs, hypertension tops the ranks followed by diet low in fruits, high BMI, diet high in sodium, smoking [5]. Modifiable risk factors contribute to $90.5 \%$ of the global stroke burden when measured in terms of DALYs [5]. The most important of these are behavioral factors such as smoking, alcohol consumption and low physical activity and metabolic factors such as high systolic blood pressure, high body mass index, diabetes, and high total cholesterol [2, 5]. In addition, environmental factors also contribute to stroke-related DALYs. Non-modifiable risk factors such as genetics also have their own contribution [2]. The increase in the modifiable risk factors could be the driving force behind the higher incidence of stroke in younger adults. ${ }^{3}$ The high contribution of modifiable risk factors means that much focus should be given on these factors to bring significant changes on the global burdens of stroke [5].

Over the past few decades, the incidence of stroke showed divergent trends between high-income countries (HICs) and low- to middle-income countries (LMICs). While the annual incidence of stroke declined in HICs, it increased in the LMICs by more than $100 \%$ to surpass that of the HIC. ${ }^{6}$ The burden in LMICs has also been higher in terms of prevalence, deaths, and DALYs lost [3,6].Previous studies reported different rate of mortality of stroke ranged from (11.97\%-60\%)[7-8]which indicate the requirement of comprehensive data on stroke mortality globally.

Advancement in technology and management of stroke led to the emergence of stroke units. According to the world health organization (WHO) action plan, access to elements of stroke unit care are considered essential [9]. Compared to general wards, these resource-intensive facilities have been associated with improved treatment outcomes in stroke patients in terms of mortality and dependency [10]. Though stroke units improve stroke outcomes both in HICs and LMICs, there are several barriers and only limited stroke units in LMICs [11-13].This coupled with the delay in hospital arrival, lack of stroke experts, shortage of medications, and cost could have potentially contributed to the poorer stroke treatment outcomes in LMICs when compared to HICs [2-3].

Currently, the global prevalence, morality and DALYs lost secondary to stroke showed a significant increase [3].However, global data on stroke mortality remained to be sparse. In light of this, we aimed to conduct a Meta-analysis and systematic review of observational studies to estimate the mortality of stroke and to identify risk factors that predispose for stroke-related death.

\section{Methods}

\section{Literature search strategies}

This study was conducted based on the Meta-Analyses of Observational Studies in Epidemiology (MOOSE) guidelines [14]. We utilized four electronic databases (google scholar, Scopus, PubMed, Embase) to retrieve articles using the following key words and mesh terms: stroke OR "ischemic stroke”* OR "acute stroke" [Mesh] OR "cerebral stroke"[Mesh] or hemorrhagic stroke AND "overall mortal*” or "30-day mortal*” or * in-hospital mortal*"[all field] OR outcome OR progno*[all field]. The search- date ranged from January, 1, 2000 to December, 25, 2017).

\section{Eligibility criteria}

We included studies measuring mortality of stroke. However, mortality from heat stroke and electric shock stroke was excluded. Age was restricted to adults (18 years of age or older). Interventional and review articles were not included in the present study.

\section{Outcome measures of the study}


Overall mortality due to stroke, in-hospital and 30-day mortality were the primary outcome measures of the study. Risk factors for stroke which constitute factors that predict the incidence of stroke and mortality were also identified.

\section{Data Collection Process}

A preliminary reading of titles and abstracts was carried out to include all relevant papers. Final inclusion of articles was made upon a thorough reading of full texts. Three investigators namely (TMA, BMG, MAS) undertook the independent review of all articles. In cases of disagreement, a fourth author (EAG) was involved and any discrepancy was resolved in consensus.

\section{Data extraction}

All records that were found from searches of the electronic databases were exported into the ENDNOTE software version X5 (Thomson Reuters, USA) so as to avoid duplication. Specific datasheet was prepared using Microsoft Excel software version 2013. Information on studies including year of publication, objectives of the study, sociodemographic and clinical characteristics of participants, complications of stroke, risk factors and types of stroke was taken from each study. The mortality rate of stroke reported as overall mortality, in-hospital mortality and 30-days mortality was fetched and stored in an independent sheet stated/leveled as "main analysis".

\section{Data analysis}

The meta-analysis was performed using Stata (Version 14, Stata Corp, College Station, Texas) [15]. Heterogeneity and publication bias were assessed using Comprehensive Meta-analysis version-3 (Biostat, Englewood, NewJersey, USA).Results were summarized using conventional forest plots. Random-effects models for estimating pooled effects were considered preferable rather than fixed-effect models because high variability across the included studies was expected. The heterogeneity in pooled estimation was determined by the DerSimonian-Laird (DL) approach and was assessed using $\mathrm{I}^{2}$. Sensitivity analysis was conducted to determine the robustness of the results and sources of variation in pooled estimation, respectively. Subgroup analysis was performed based on study design and geography of study subjects. Moreover, publication bias for the primary outcome was assessed by Egger test and inspection of funnel plots. The quality of the studies was evaluated using STROBE (Strengthening the Reporting of Observational Studies in Epidemiology) scale [16]. Accordingly, we arbitrarily classified included studies into high quality ( $\geq 75 \%$ of the STROBE checklist) and low quality ( $<75 \%$ of the STROBE checklist).

\section{Results}

\section{Study characteristics and the selection process}

Overall, 8408 records were generated from four electronic databases including PubMed (1654), Scopus (2857), Google scholar (3670) and Embase databases (227), respectively. No grey literature was included. The preliminary screening based on titles and abstracts identified forty-one papers as potentially relevant for the full-text review and thirty two articles were finally deemed eligible for the systematic review and meta-analysis (fig 1).

Thirty two studies assessed overall mortality due to stroke. Twelve studies were from Africa [7-8, 17-26], six from Europe [27-32], six from Asia [33-38], five from North America [39-43] and two from Latin America [44-45].Seventeen studies reported 30-day mortality rate of stroke whereas twenty two studies measured in-hospital mortality. Detailed explanations on study characteristics are shown in the supplementary table (table 1).

\section{Patient Characteristics}

A total number of 2,885, 126 patients were recruited for the study. The mean age of participants was found to be $69.8 \pm 13.8$ years. There were $1172581(40.64 \%)$ males and 1712545(59.36\%) females, respectively. Overall stroke mortality was documented for 302,592 (10.49\%) patients. The rate of 30day mortality was reported in $19057(0.66 \%)$ subjects while in-hospital mortality was recorded in 108, 368 (3.75\%) participants.

\section{Types of stroke}

About 1213064 (42\%) patients experienced ischemic stroke. hemorrhagic stroke was identified in 190,906(6.6\%) of patients. The remaining stroke events were undifferentiated or unclassified.

\section{Risk factors}

The following risk factors were reported hypertension 1159461(40.2\%) with mean systolic blood pressure of $154.29 \pm 21.45 \mathrm{mmHg}$, diabetes 195612 (6.78), AF: 216097 (7.49\%), hypercholesterolemia: 420144 (14.5\%), alcohol consumption: 30902 (1.71\%), smoking: 163583 (5.67\%), cardiomyopathy 3987(0.14\%) and previous stroke attack $39833(1.4 \%)$. The risk factors for rest of the population were not distinguished.

\section{Complications of stroke}

Complications were reported in 10,622subjects. Specific complications include confusion $4629(43.57 \%)$, thromboembolism $170(1.6 \%)$, mobility disorder $1573(14.81 \%)$, speech disorder 1550(14.59\%), infection 465(4.38\%), cognitive problem 731(6.9\%), neurologic complications $1504(14.16 \%)$.

\section{Mortality of stroke}

Pooled estimate indicated that the overall mortality of stroke was reported to be $20 \%$ ( $19 \%-22 \%)$. Whereas, the 30 -day mortality was found to be $18 \%$ (16\%-20\%). In-hospital mortality was estimated as 16\% (16\%-19\%) (Fig 2-4). 


\section{Subgroup analysis}

To examine the difference in the epidemiology of stroke mortality among continents and type of study designs, a subgroup analysis was undertaken based on the location of the studies and study designs. Consequently, It was found that Africa registered the highest stroke-related death $29 \%$ (23\%-36\%) followed by Europe 22\% (16\%-27\%). (Fig. 5) America, 16\% (12\%-20\%) and Asia 16\% (10\%-21\%) showed a comparable rate of overall stroke mortality (Figure 5).Mortality was higher among prospective studies $26 \%$ (22\%-31\%) versus retrospective $17 \%$ (15\%-20\%) (Additional file 1).

\section{Determinants of mortality}

Pooled odds ratio of precipitating factors revealed that hypertension was found to be an important risk factor for mortality secondary to stroke $61.9 \%$ (52.8\%-71.1\%). The probability of death has increased in a quarter among stroke patients who were having hypercholesterolemia $20.2 \%(10.0 \%-30.4 \%)$ and alcohol consumption $21.5 \%(10.4 \%-32.6 \%)$, respectively (table 2$)$.

\section{Sensitivity and subgroup analysis}

The sensitivity analysis showed that omission of anyone of the included studies did not significantly affect the pooled mortality of stroke (all P $<0.05$ ) (additional file 2). We performed subgroup analysis based on geographic area of the studies and the type of study design. Accordingly, overall mortality was found to be higher in Africa $29 \%$ (23\%-36\%) than any other continents (fig 5 ).In addition, mortality was higher among prospective studies $26 \%$ (22\%-31\%) versus retrospective $17 \%$ (15\%-20\%) (Additional file 3).

\section{Discussion}

Stroke is a sudden cerebrovascular accident that poses significant mortality and morbidity. Stroke mortality can be summarized as overall mortality, 30-day mortality and in-hospital mortality. Post-stroke complications of stroke denotes a constellation of disabilities including: neurologic sequelae, infection, psychiatric disorder, pain, movement disorders, cognitive and speech problems [46]. The determinants of mortality secondary to stroke represent an array of modifiable and non-modifiable risk factors including diabetes [47], hypertension [48], hypercholesterolemia [49], alcohol consumption [50], cigarette smoking [51] and atrial fibrillation [52].Despite the hassle burden of stroke, data regarding stroke mortality and its determinants were found to be scarce. To this end, a systematic review and meta-analysis of observational studies has been designed so as to explore the mortality rate of stroke on the basis of gross, thirty-day and in-hospital mortalities. In addition, the current review highlighted risk factors that implicate with stroke mortality.

A rigorous review of 32 articles provided a total of 2,885, 126 stroke patients. According to the pooled analysis, the overall mortality of stroke was reported to be $20 \%$ (Cl: $19 \%-22 \%$ ). This figure falls between ranges of mortality values reported by different studies. ${ }^{7-8}$ Subgroup analysis confirmed greater incidence of overall stroke mortality in Africa29\% (23\%-36\%). In Africa, the burden of stroke appeared to be in unprecedented rise which cause international inequality in relative to developed nations. Contemporary reports indicated 316 per 100000 incidence rate of stroke per year. Socio-demographic and lifestyle changes in the general population including population growth and longevity were supposed to attribute for this substantial burden [53-54].Ironically, there is limited intervention to reduce the impact of stroke on the lives of individuals. For instance, African counties lack national strategies to stop smoking, alcohol consumption and to promote physical activity [54-55].To date; there is no "state of the art" stroke care in African countries. Rather, the management of stroke is directed to supportive therapies. Further, diagnosis is speculative and complex due to lack of imaging modalities. Patients' pre hospital delay precludes the timely initiation of thrombolytic therapy [56].In contrary, low rate of crude mortality was observed in Europe (22\%), America (16\%), and Asia (16\%). Recent advances in system and processes enable developed countries to efficiently use reperfusion therapy. Reperfusion improves outcomes by reducing the volume of brain tissue injury. Tele-stroke and mobile stroke units in the pre hospital setting have increased thrombolytic utilization and reduced delays to treatment. However, these technologies are hardly implemented in low and middle income countries despite their effectiveness [57].

30-day mortality was found to be $18 \%(16 \%-20 \%)$ in the present review. Different explanations have been forwarded for the escalated burden of mortality in stroke patients within thirty days of the stroke event. Among ischemic stroke patients, the mortality of stroke depends on the efficacy of anticoagulation and the mortality associated with intracranial hemorrhage due to the supra-therapeutic anticoagulation [58]. We can extrapolate that the 30-day mortality is not independently attributed from stroke, rather it could be secondary to the bleeding related to anticoagulation. In addition, the thirty-day mortality could be influenced by integrated system of stroke care. For instance, retrospective analysis of a large data base of Canadian stoke registry reported a significant decline of 30 -day mortality to $12.7 \%$ in well-organized stroke center. However, the magnitude of 30 -day mortality of stroke is expected to be significant in developing countries where advanced stroke service and nursing care is inadequate [59].A prospective evaluation of death among Nigerian stroke patients with thirty days of ictus reported a $19.69 \%$ of mortality which is nearly a similar figure with the pooled estimate [17]. A multi-center analysis of large data of acute ischemic stroke patients in United States revealed 15.32\% 30-day mortality. ${ }^{39}$ In United Kingdom, time-trend analysis of the general practice research stroke database indicated similar rate of mortality (15.32\%) [32].

Further, the present review included 108,368 subjects from 22 articles to determine the in-hospital mortality of stroke. Accordingly, the pooled in-hospital mortality was found to be $16 \%$ (14\%-19\%). The frequency of in-hospital mortality was reported among different countries such Iran 20.52\% [34] Sweden(15.47\%) [19] and Cameroon 20.62\% [30]. Even though hospital admission facilitates the recovery of stoke patients, in the meantime, it predisposes patients for hospital acquired infections which complicate the survival of stroke patients. More importantly, the likelihood of in-hospital mortality is substantiallyaffected by the prompt and vigilant care. ${ }^{60}$ In addition, the coincidence of comorbidities such as diabetes, AF and other cardiovascular disorders deteriorates the prognosis of patients admitted with stroke. ${ }^{61}$ Increased risk of in-hospital mortalitywas also noted in patients who were presented withsevere form of stroke manly middle cerebral artery occlusion with herniation, basilar artery occlusion, and hemorrhagic transformation [62].Therefore, the contribution of in-hospital mortality for the burden of overall mortality of stroke could be minimized through delivery of pragmatic care for hospitalized stroke patients. 
Our review highlighted that, hypertension was the most common precipitating factor for the onset of stroke and subsequent death. HTN accounted to a $61.9 \%$ (52.8-71.1) increase in the incidence of mortality. The occurrence of stroke on the top of elevated blood pressure is viewed as one of the hypertensive crisis encountered in emergency department. The prompt management of hypertensive emergency determines the prognosis of patients. Hemorrhagic transformation of ischemic stroke is a clinical deterioration and the most fatal scenario observed in patients who are not properly managed in critical setting. Poor outcome was noticed in hemorrhagic stroke patients due to the development of hematoma. Therefore, adequate blood pressure should be a priority so as to reduce the mortality of stroke $[48,63]$.We also investigated other risk factors such as diabetes, AF and dyslipidemia as independent determinants that influence stroke outcomes. Additional studies are warranted to explore strategies to minimize the consequence of these risk factors on stroke mortality.

In general, the current review revealed that the mortality of stroke found to be more significant worldwide to the extent that it becomes a huge hassle for the global health. But, the study was not without limitations. Firstly, some of the studies included in the review showed higher level of heterogeneity and we could not detect the source of variation with the available data. However, we conducted a sensitivity analysis to avoid the 'drowning effect' from large sample size studies. For example, one-on-one exclusionof Margaret C et al 2014 [41] and Agarwal S et al 2015[42]found that the overall mortality did not differ from the original overall estimates.Secondly, it should be noticed that data regarding mortality might not be comprehensive since information from grey literatures were not searched.

\section{Conclusions}

Overall mortality of stroke was estimated to be twenty percent. The burden of stroke mortality was prominent in Africa region. Hypertension remained to be an independent risk factor for stroke mortality. On the basis of the findings of the present review, it is recommended that the overall mortality of stroke can be minimized by establishing stroke centers that promptly deliver emergency management of stroke event. Particularly, these services should be extended in African region which represent the highest rate of mortality due to stroke. Further, blood pressure control should be given a due attention to reduce the risk of mortality secondary to cerebrovascular incidence.

\section{Abbreviations}

$\begin{array}{ll}\text { AHA } & \text { American Heart Association } \\ \text { ASA } & \text { American Stroke Association } \\ \text { CNS } & \text { central nervous system } \\ \text { DALYs } & \text { Disability Adjusted Life Years } \\ \text { GBD } & \text { Global Burden of Diseases } \\ \text { HICs } & \text { high-income countries } \\ \text { HTN } & \text { Hypertension } \\ \text { IS } & \text { ischemic stroke } \\ \text { ICH } & \text { intracerebral hemorrhage } \\ \text { LMICs } & \text { Low- to middle-income countries } \\ \text { MOOSE: } & \text { Meta-Analyses of Observational Studies in Epidemiology } \\ \text { SAH } & \text { subarachnoid hemorrhage } \\ \text { STROBE } & \text { Strengthening the Reporting of Observational Studies in Epidemiology } \\ \text { WHO } & \text { world health organization }\end{array}$

\section{Declarations}

\section{Ethics approval and consent to participate}

Not applicable

\section{Consent to publish}

Not applicable

\section{Availability of data and materials}

All data are included in the main manuscript and additional files

\section{Competing interests}


Authors declared no conflict of interest

\section{Funding}

This study did not receive any fund

\section{Authors' Contributions}

TMA conceived the study, prepared the study protocol, involve in acquisition of data, performed review, and analyze the data and write-up of the final part of the manuscript. MAS, EAG, AGM, ASB, MBA and BMG prepared the study protocol, interpret and analyzed the data and wrote the initial draft of manuscript. All the authors read, approved the final manuscript and agreed to be accountable for all aspects of the work.

\section{Acknowledgments}

We thank university of Gondar, college of medicine and health sciences for overall support.

\section{References}

1. Sacco RL, Kasner SE, Broderick JP, Caplan LR, Culebras A, Elkind MS, et al. An updated definition of stroke for the 21 st century: a statement for healthcare professionals from the American Heart Association/American Stroke Association. Stroke. 2013;44(7):2064-89.

2. Benjamin EJ, Blaha MJ, Chiuve SE, Cushman M, Das SR, Deo R, et al. Heart disease and stroke statistics-2017 update: a report from the American Heart Association. Circulation. 2017;135(10):e146-e603.

3. Feigin VL, Norrving B, Mensah GA. Global Burden of Stroke. Circulation research. 2017;120(3):439-48.

4. Feigin VL, Lawes CM, Bennett DA, Barker-Collo SL, Parag V. Worldwide stroke incidence and early case fatality reported in 56 population-based studies: a systematic review. The Lancet Neurology. 2009;8(4):355-69.

5. Feigin VL, Roth GA, Naghavi M, Parmar P, Krishnamurthi R, Chugh S, et al. Global burden of stroke and risk factors in 188 countries, during $1990-2013$ : a systematic analysis for the Global Burden of Disease Study 2013. The Lancet Neurology. 2016;15(9):913-24.

6. Feigin VL, Forouzanfar MH, Krishnamurthi R, Mensah GA, Connor M, Bennett DA, et al. Global and regional burden of stroke during 1990-2010: findings from the Global Burden of Disease Study 2010. The Lancet. 2014;383(9913):245-55.

7. Gebremariam SA, Yang HS. Types, risk profiles, and outcomes of stroke patients in a tertiary teaching hospital in northern Ethiopia. eNeurologicalSci. 2016;3:41-7.

8. Walker R, Jusabani A, Aris E, Gray W, Mugusi F, Swai M, et al. Correlates of short-and long-term case fatality within an incident stroke population in Tanzania. SAMJ: South African Medical Journal. 2013;103(2):107-12.

9. Lindsay P, Furie KL, Davis SM, Donnan GA, Norrving B. World Stroke Organization global stroke services guidelines and action plan. International Journal of Stroke. 2014;9(A100):4-13.

10. Trialists'Collaboration SU. Organised inpatient (stroke unit) care for stroke. The Cochrane database of systematic reviews. 2013;9(9).

11. Langhorne P, de Villiers L, Pandian JD. Applicability of stroke-unit care to low-income and middle-income countries. The Lancet Neurology. 2012;11(4):341-8.

12. Pandian JD, William AG, Kate MP, Norrving B, Mensah GA, Davis S, et al. Strategies to improve stroke care services in low-and middle-income countries: a systematic review. Neuroepidemiology. 2017;49(1-2):45-61.

13. Khatib R, Jawaada AM, Arevalo YA, Hamed HK, Mohammed SH, Huffman MD. Implementing Evidence-Based Practices for Acute Stroke Care in Low-and Middle-Income Countries. Current atherosclerosis reports. 2017;19(12):61.

14. Stroup DF, Berlin JA, Morton SC, Olkin I, Williamson GD, Rennie D, et al. Meta-analysis of observational studies in epidemiology: a proposal for reporting. Jama. 2000;283(15):2008-12.

15.StataCorp L. Stata Statistical Software: Release 14.[computer program]. StataCorp LP 2015. .

16. von Elm E, Altman DG, Egger M, Pocock SJ, Gotzsche PC, Vandenbroucke JP. The Strengthening the Reporting of Observational Studies in Epidemiology (STROBE) statement: guidelines for reporting observational studies. Journal of clinical epidemiology. 2008;61(4):344-9.

17. Sanya EO, Wahab K, Bello A, Alaofin W, Ademiluyi B. In-hospital stroke mortality and its predictors within one month of ictus: Result from a tertiary hospital in Ilorin, middle belt Nigeria. Sub-Saharan African Journal of Medicine. 2015;2(4):165.

18. Mapoure N, Tchaleu Nguenkam C, Mbatchou Ngahane H, Dzudie A, Coulibaly A, Mounjouopou N, et al. Predictors of in-hospital mortality for stroke in Douala, Cameroon. Stroke research and treatment. 2014;2014.

19. Lekoubou A, Nkoke C, Dudzie A, Kengne AP. Computed tomography scanning and stroke mortality in an urban medical unit in Cameroon. eNeurologicalSci. 2016;2:3-7.

20. Gnonlonfoun DD, Adjien C, Ossou-Nguiet PM, Avlessi I, Goudjinou G, Houannou O, et al. Stroke: Medium and long-term mortality and associated factors in French-speaking West Africa, case of Benin. World Journal of Neuroscience. 2014;4(01):68.

21. Atadzhanov M, N Mukomena P, Lakhi S, A Ross O, F Meschia J. Stroke characteristics and outcomes of adult patients admitted to the University Teaching Hospital, Lusaka, Zambia. The Open General and Internal Medicine Journal. 2012;5(1). 
22. Heikinheimo T, Chimbayo D, Kumwenda JJ, Kampondeni S, Allain TJ. Stroke outcomes in Malawi, a country with high prevalence of HIV: a prospective follow-up study. PloS one. 2012;7(3):e33765.

23. Ekeh B, Ogunniyi A, Isamade E, Ekrikpo U. Stroke mortality and its predictors in a Nigerian teaching hospital. African health sciences. 2015;15(1):74-80.

24. Alkali NH, Bwala SA, Akano AO, Osi-Ogbu O, Alabi P, Ayeni OA. Stroke risk factors, subtypes, and 30-day case fatality in Abuja, Nigeria. Nigerian medical journal: journal of the Nigeria Medical Association. 2013;54(2):129.

25. Nakibuuka J, Sajatovic M, Nankabirwa J, Ssendikadiwa C, Furlan AJ, Katabira E, et al. Early mortality and functional outcome after acute stroke in Uganda: prospective study with 30 day follow-up. Springerplus. 2015;4:450.

26. Deresse B, Shaweno D. Epidemiology and in-hospital outcome of stroke in South Ethiopia. Journal of the neurological sciences. 2015;355(1):138-42.

27. Rutten-Jacobs LC, Arntz RM, Maaijwee NA, Schoonderwaldt HC, Dorresteijn LD, van Dijk EJ, et al. Long-term mortality after stroke among adults aged 18 to 50 years. Jama. 2013;309(11):1136-44.

28. Mathisen SM, Dalen I, Larsen JP, Kurz M. Long-term mortality and its risk factors in stroke survivors. Journal of Stroke and Cerebrovascular Diseases. 2016;25(3):635-41.

29. Grau AJ, Weimar C, Buggle F, Heinrich A, Goertler M, Neumaier S, et al. Risk factors, outcome, and treatment in subtypes of ischemic stroke: the German stroke data bank. Stroke. 2001;32(11):2559-66.

30. Garcia-Ptacek S, Escamez BC, Zupanic E, Religa D, von Koch L, Johnell K, et al. Prestroke Mobility and Dementia as Predictors of Stroke Outcomes in Patients Over 65 Years of Age: A Cohort Study From The Swedish Dementia and Stroke Registries. Journal of the American Medical Directors Association. 2017.

31. Goldacre MJ, Duncan M, Griffith M, Rothwell PM. Mortality rates for stroke in England from 1979 to 2004: trends, diagnostic precision, and artifacts. Stroke. 2008;39(8):2197-203.

32. Lee S, Shafe AC, Cowie MR. UK stroke incidence, mortality and cardiovascular risk management 1999-2008: time-trend analysis from the General Practice Research Database. BMJ open. 2011;1(2):e000269.

33. Ghandehari K, Izadi-Mood Z. Khorasan stroke registry: analysis of 1392 stroke patients. Arch Iran Med. 2007;10(3):327-34.

34. Farhoudi M, Mehrvar K, Sadeghi-Bazargani H, Hashemilar M, Seyedi-Vafaee M, Sadeghi-Hokmabad E, et al. Stroke subtypes, risk factors and mortality rate in northwest of Iran. Iranian journal of neurology. 2017;16(3):112.

35. Wang W, Jiang B, Sun H, Ru X, Sun D, Wang L, et al. Prevalence, Incidence, and Mortality of Stroke in China: Results from a Nationwide Population-Based Survey of 480687 Adults. Circulation. 2017;135(8):759-71.

36. Tan Y, Pan Y, Liu L, Wang Y, Zhao X, Wang Y, et al. One-year outcomes and secondary prevention in patients after acute minor stroke: results from the China National Stroke Registry. Neurological research. 2017;39(6):484-91.

37. Nayak AR, Shekhawat SD, Lande NH, Kawle AP, Kabra DP, Chandak NH, et al. Incidence and clinical outcome of patients with hypertensive acute ischemic stroke: An update from Tertiary Care Center of Central India. Basic and clinical neuroscience. 2016;7(4):351.

38. Sylaja P, Pandian JD, Kaul S, Srivastava MP, Khurana D, Schwamm LH, et al. Ischemic Stroke Profile, Risk Factors, and Outcomes in India: The Indo-US Collaborative Stroke Project. Stroke. 2018;49(1):219-22.

39. Golestanian E, Liou J-I, Smith MA. Long-term survival in older critically ill patients with acute ischemic stroke. Critical care medicine. 2009;37(12):3107.

40. Ledneva T. In-Hospital/30 -Day Stroke Mortality Risk Adjusted Rate Development, SPARCS, 2013

41. Fang MC, Perraillon MC, Ghosh K, Cutler DM, Rosen AB. Trends in stroke rates, risk, and outcomes in the United States, 1988 to 2008 . The American journal of medicine. 2014;127(7):608-15.

42. Agarwal S, Menon V, Jaber WA. Outcomes after acute ischemic stroke in the United States: does residential ZIP code matter? Journal of the American Heart Association. 2015;4(3):e001629.

43. Ganesh A, Lindsay P, Fang J, Kapral MK, Cote R, Joiner I, et al. Integrated systems of stroke care and reduction in 30-day mortality: A retrospective analysis. Neurology. 2016;86(10):898-904.

44. de Carvalho JJF, Alves MB, Viana GAA, Machado CB, dos Santos BFC, Kanamura AH, et al. Stroke Epidemiology, Patterns of Management, and Outcomes in Fortaleza, Brazil. 2011.

45. Kuster GW, Dutra LA, Brasil IP, Pacheco EP, Arruda MA, Volcov C, et al. Outcome determinants of stroke in a Brazilian primary stroke center. Stroke research and treatment. 2014;2014.

46. Langhorne P, Stott D, Robertson L, MacDonald J, Jones L, McAlpine C, et al. Medical complications after stroke: a multicenter study. Stroke. 2000;31(6):1223-9.

47. Tuomilehto J, Rastenytė D, Jousilahti P, Sarti C, Vartiainen E. Diabetes mellitus as a risk factor for death from stroke: prospective study of the middle-aged Finnish population. Stroke. 1996;27(2):210-5.

48. Redon J, Olsen MH, Cooper RS, Zurriaga O, Martinez-Beneito MA, Laurent S, et al. Stroke mortality and trends from 1990 to 2006 in 39 countries from Europe and Central Asia: implications for control of high blood pressure. European heart journal. 2011;32(11):1424-31.

49. Piechowski-Jóźwiak B, Bogousslavsky J. Cholesterol as a risk factor for stroke: the fugitive? Stroke. 2004;35(6):1523-4.

50. Zhang C, Qin Y-Y, Chen Q, Jiang H, Chen X-Z, Xu C-L, et al. Alcohol intake and risk of stroke: a dose-response meta-analysis of prospective studies. International journal of cardiology. 2014;174(3):669-77.

51. Ueshima H, Choudhury SR, Okayama A, Hayakawa T, Kita Y, Kadowaki T, et al. Cigarette smoking as a risk factor for stroke death in Japan: NIPPON DATA80. Stroke. 2004;35(8):1836-41. 
52. Wolf PA, Abbott RD, Kannel WB. Atrial fibrillation as an independent risk factor for stroke: the Framingham Study. Stroke. 1991;22(8):983-8.

53. Owolabi MO, Arulogun O, Melikam S, Adeoye AM, Akarolo-Anthony S, Akinyemi R, et al. The burden of stroke in Africa: a glance at the present and a glimpse into the future. Cardiovascular journal of Africa. 2015;26(Supplement 1):27-38.

54. Adeloye D. An estimate of the incidence and prevalence of stroke in Africa: a systematic review and meta-analysis. PLoS One. 2014;9(6):e100724.

55. Owolabi M, Olowoyo P, Popoola F, Lackland D, Jenkins C, Arulogun O, et al. The epidemiology of stroke in Africa: A systematic review of existing methods and new approaches. The Journal of Clinical Hypertension. 2018;20(1):47-55.

56. Bertha Chioma Ekeh Challenges of the Management of Stroke in Sub Saharan Africa: Evaluating Awareness AaAJPNM, Vol 2(3) DOI: 10.4172/2472100X.1000128. Challenges of the Management of Stroke in Sub Saharan Africa: Evaluating Awareness, Access and Action. J Pediatr Neurol Med, Vol 2(3) DOI: $10.4172 / 2472-100 X .1000128$.

57. Chang P, Prabhakaran S. Recent advances in the management of acute ischemic stroke. F1000Research. 2017;6.

58. Fang MC, Go AS, Chang Y, Borowsky LH, Pomernacki NK, Udaltsova N, et al. Thirty-day mortality after ischemic stroke and intracranial hemorrhage in patients with atrial fibrillation on and off anticoagulants. Stroke. 2012;43(7):1795-9.

59. Myint PK, O. Bachmann M, Loke YK, D. Musgrave S, Price GM, Hale R, et al. Important factors in predicting mortality outcome from stroke: findings from the Anglia Stroke Clinical Network Evaluation Study. Age and ageing. 2016;46(1):83-90.

60. Ameriso S, Povedano G, Díaz M, Hlavnicka A, Wainsztein N, Ameriso S. In-hospital mortality due to stroke. Medicina. 2013;73(4):331-4.

61. Meira F, Dorim D, Andrade AC, Santos T, Magalhães D, Ladeia L, et al. Analysis of Risk Factors for In-Hospital Stroke Mortality and Stroke Readmission in Hospital Risoleta Tolentino Neves (HRTN)-Belo Horizonte, Brazil (P1. 213). Neurology. 2016;86(16 Supplement):P1. 213.

62. Ong C-T, Sung S-F, Wong Y-S, Wu C-S, Hsu Y-C, Su Y-H, et al. Risk Factors for In-Hospital Mortality among Ischemic Stroke Patients in Southern Taiwan. International Journal of Gerontology. 2016;10(2):86-90.

63. Berger C, Fiorelli M, Steiner T, Schäbitz W-R, Bozzao L, Bluhmki E, et al. Hemorrhagic transformation of ischemic brain tissue: asymptomatic or symptomatic? Stroke. 2001;32(6):1330-5.

\section{Tables}


Table 1. Overview of studies included in the systematic review and meta-analysis

\begin{tabular}{|c|c|c|c|c|c|c|c|c|c|c|c|c|c|c|}
\hline \multirow[t]{2}{*}{ Study } & \multirow[t]{2}{*}{ Design } & \multirow[t]{2}{*}{ Location } & \multirow{2}{*}{$\begin{array}{l}\text { Sample } \\
\text { size }\end{array}$} & \multirow{2}{*}{$\begin{array}{l}\text { Mean age, } \\
\text { years }\end{array}$} & \multirow[t]{2}{*}{ Sex(M:F) } & \multicolumn{3}{|c|}{ Outcomes } & \multicolumn{6}{|c|}{ Risk factors } \\
\hline & & & & & & $\begin{array}{l}\text { Overall } \\
\text { mortality }\end{array}$ & $\begin{array}{l}\text { 30-days } \\
\text { mortality }\end{array}$ & $\begin{array}{l}\text { In- } \\
\text { hospital } \\
\text { mortality }\end{array}$ & HTN & $\mathrm{DM}$ & $\mathrm{AF}$ & Alcohol & Smoking & $\overline{\mathrm{H}}$ \\
\hline $\begin{array}{l}\text { Sanya } \text { EO } \\
\text { et al } 2015\end{array}$ & Prospective & Nigeria & 302 & $60.47 \pm 13.60$ & $161: 133$ & 64 & 64 & 64 & $\sqrt{ }$ & & - & $\sqrt{ }$ & $\sqrt{ }$ & $\sqrt{ }$ \\
\hline $\begin{array}{l}\text { Mapoure NY } \\
\text { et et al } 2014\end{array}$ & Prospective & Cameroon & 325 & $58.66 \pm 13.6$ & $201: 124$ & 87 & 87 & 87 & $\sqrt{ }$ & $\sqrt{ }$ & - & - & - & $\sqrt{ }$ \\
\hline $\begin{array}{l}\text { Lekoubou A } \\
\text { etal } 2016\end{array}$ & Retrospective & Cameroon & 1688 & 62.7 & $846: 840$ & 348 & 348 & 348 & $\sqrt{ }$ & $\sqrt{ }$ & - & $\sqrt{ }$ & $\sqrt{ }$ & - \\
\hline $\begin{array}{l}\text { Golestanian } \\
\text { E etal } 2009\end{array}$ & Retrospective & USA & 31303 & $79.9 \pm 7.6$ & 11738:19563 & 10626 & 4795 & 3248 & $\sqrt{ }$ & $\sqrt{ }$ & - & - & - & - \\
\hline $\begin{array}{l}\text { Walker RW } \\
\text { et al } 2013\end{array}$ & \begin{tabular}{|l|} 
Cross- \\
sectional \\
study \\
\end{tabular} & Tanzania & 130 & $68.8 \pm 14.8$ & & 78 & 31 & - & $\sqrt{ }$ & $\sqrt{ }$ & - & - & $\sqrt{ }$ & $\sqrt{\sqrt{ }}$ \\
\hline $\begin{array}{l}\text { Gnonlonfoun } \\
\text { DD et al } \\
2014\end{array}$ & $\begin{array}{l}\text { Cross- } \\
\text { sectional } \\
\text { study } \\
\end{array}$ & Benin & 100 & - & $58: 42$ & 29 & - & - & $\sqrt{ }$ & $\sqrt{ }$ & - & - & - & $\sqrt{\sqrt{ }}$ \\
\hline \begin{tabular}{l}
\multicolumn{2}{l}{ Mathisen } \\
SM etal \\
2015
\end{tabular} & Retrospective & Norway & 1137 & $66.8 \pm 14.3$ & $611: 526$ & 589 & - & - & $\sqrt{ }$ & $\sqrt{ }$ & $\sqrt{ }$ & - & $\sqrt{ }$ & $\sqrt{ }$ \\
\hline $\begin{array}{l}\text { Loes CA et } \\
\text { al } 2013\end{array}$ & $\begin{array}{l}\text { Prospective } \\
\text { study }\end{array}$ & Netherlands & 959 & - & $446: 513$ & 192 & 43 & - & $\sqrt{ }$ & $\sqrt{ }$ & $\sqrt{ }$ & $\sqrt{ }$ & $\sqrt{ }$ & - \\
\hline $\begin{array}{l}\text { Atadzhanov } \\
\text { M et al } 2012\end{array}$ & $\begin{array}{l}\text { Cross- } \\
\text { sectional } \\
\end{array}$ & Zambia & 250 & $55 \pm 18$ & $103: 147$ & 101 & 101 & 101 & $\sqrt{ }$ & $\sqrt{ }$ & $\sqrt{ }$ & $\sqrt{ }$ & $\sqrt{ }$ & $\sqrt{\sqrt{ }}$ \\
\hline $\begin{array}{ll}\text { Sennay } & \text { A } \\
\text { etal 2016 } & \end{array}$ & Retrospective & Ethiopia & 142 & $62.8 \pm 15.6$ & $77: 65$ & 17 & 17 & 17 & $\sqrt{ }$ & $\sqrt{ }$ & $\sqrt{ }$ & $\sqrt{ }$ & - & - \\
\hline $\begin{array}{l}\text { Heikinheimo } \\
\text { T et al } 2012\end{array}$ & Prospective & Malawi & 147 & $54.2 \pm 16.9$ & $76: 71$ & 59 & - & 33 & $\sqrt{ }$ & $\sqrt{ }$ & - & - & $\sqrt{ }$ & $\sqrt{ }$ \\
\hline $\begin{array}{ll}\text { Deresse } & \text { B } \\
\text { et al } 2015 & \\
\end{array}$ & $\begin{array}{l}\text { Prospective } \\
\text { study }\end{array}$ & Ethiopia & 163 & $53.1 \pm 16.9$ & 108:55 & 24 & 24 & 24 & $\sqrt{ }$ & $\sqrt{ }$ & $\sqrt{ }$ & $\sqrt{ }$ & $\sqrt{ }$ & $\sqrt{ }$ \\
\hline $\begin{array}{l}\text { Ekeh B et } \\
\text { al } 2015\end{array}$ & Prospective & Nigeria & 120 & $55 \pm 15.2$ & $74: 46$ & 42 & 30 & - & $\sqrt{ }$ & $\sqrt{ }$ & - & - & - & $\sqrt{\sqrt{ }}$ \\
\hline $\begin{array}{l}\text { Nura H etal } \\
2013\end{array}$ & Prospective & Nigeria & 272 & $56.4 \pm 12.7$ & $168: 104$ & 51 & 51 & 49 & $\sqrt{ }$ & $\sqrt{ }$ & $\sqrt{ }$ & - & $\sqrt{ }$ & $\sqrt{ }$ \\
\hline $\begin{array}{l}\text { Nakibuuka J } \\
\text { et al } 2015\end{array}$ & Prospective & Uganda & 127 & - & $59: 68$ & 42 & 42 & 23 & $\sqrt{ }$ & $\sqrt{ }$ & $\sqrt{ }$ & - & - & - \\
\hline $\begin{array}{l}\text { Ledneva et } \\
\text { al } 2013\end{array}$ & Retrospective & USA & 28143 & - & 13416:14727 & 3943 & 3943 & 2506 & $\sqrt{ }$ & $\sqrt{ }$ & $\sqrt{ }$ & $\sqrt{ }$ & $\sqrt{ }$ & $\sqrt{ }$ \\
\hline $\begin{array}{l}\text { Armin J et al } \\
2001\end{array}$ & Retrospective & Germany & 5017 & $65.9 \pm 14.1$ & $2890: 2127$ & 519 & 519 & - & $\sqrt{ }$ & $\sqrt{ }$ & $\sqrt{ }$ & $\sqrt{ }$ & $\sqrt{ }$ & $\sqrt{\sqrt{ }}$ \\
\hline $\begin{array}{l}\text { Garcia- } \\
\text { Ptacek S et } \\
\text { al } 2017\end{array}$ & Retrospective & Sweden & 9662 & $>65$ years & $4164: 5498$ & 2364 & - & 1495 & - & $\sqrt{ }$ & $\sqrt{ }$ & - & - & - \\
\hline $\begin{array}{l}\text { Margaret C } \\
\text { et al } 2014\end{array}$ & $\begin{array}{l}\text { Cross- } \\
\text { sectional }\end{array}$ & USA & 1051342 & - & 366065:552059 & 127129 & - & - & - & - & - & - & - & - \\
\hline $\begin{array}{l}\text { Ghandehari } \\
\text { K et al } 2007\end{array}$ & Retrospective & Iran & 16351 & $63.4 \pm 17.2$ & 8759:7592 & 3354 & 3354 & - & - & - & - & - & - & - \\
\hline $\begin{array}{l}\text { Farhoudi M } \\
\text { et al } 2017\end{array}$ & Retrospective & Iran & 5355 & $67.6 \pm 13.8$ & 2708:2647 & 1099 & 1099 & 1099 & $\sqrt{ }$ & $\sqrt{ }$ & $\sqrt{ }$ & $\sqrt{ }$ & $\sqrt{ }$ & $\sqrt{ }$ \\
\hline $\begin{array}{l}\text { Wang W et } \\
\text { al } 2017\end{array}$ & $\begin{array}{l}\text { Nationwide } \\
\text { survey }\end{array}$ & China & 9315 & $46.6 \pm 16.3$ & 5120:4195 & 758 & - & 758 & $\sqrt{ }$ & $\sqrt{ }$ & $\sqrt{ }$ & $\sqrt{ }$ & $\sqrt{ }$ & $\sqrt{\sqrt{ }}$ \\
\hline $\begin{array}{l}\text { Ying Tan Y } \\
\text { et al } 2017\end{array}$ & Retrospective & China & 913 & $65.1 \pm 11.8$ & 1288:625 & 121 & - & - & $\sqrt{ }$ & $\sqrt{ }$ & $\sqrt{ }$ & $\sqrt{ }$ & $\sqrt{ }$ & $\sqrt{ }$ \\
\hline $\begin{array}{lr}\text { Freitas } & \text { de } \\
\text { Carvalho } & \mathrm{JJ} \\
\text { et al 2011 } & \\
\end{array}$ & $\begin{array}{l}\text { Prospective } \\
\text { study }\end{array}$ & Brazil & 2407 & $66.86 \pm 14.38$ & $1160: 1247$ & 503 & - & 503 & $\sqrt{ }$ & $\sqrt{ }$ & $\sqrt{ }$ & $\sqrt{ }$ & $\sqrt{ }$ & $\sqrt{ }$ \\
\hline $\begin{array}{l}\text { Nayak AR et } \\
\text { al } 2016\end{array}$ & Prospective & India & 104 & - & $73: 31$ & 53 & - & 17 & - & - & - & - & - & - \\
\hline $\begin{array}{l}\text { Sylaja PN et } \\
\text { al } 2018\end{array}$ & Prospective & India & 2066 & $58.3 \pm 14.7$ & 1389:678 & 163 & - & 163 & $\sqrt{ }$ & $\sqrt{ }$ & $\sqrt{ }$ & $\sqrt{ }$ & $\sqrt{ }$ & $\sqrt{ }$ \\
\hline $\begin{array}{ll}\text { Agarwal } & \text { S } \\
\text { et al } 2015 & \\
\end{array}$ & Retrospective & USA & 775905 & $71.65 \pm 14.475$ & $357547: 418358$ & 43425 & - & 43425 & $\sqrt{ }$ & $\sqrt{ }$ & - & $\sqrt{ }$ & $\sqrt{ }$ & $\sqrt{\sqrt{ }}$ \\
\hline $\begin{array}{l}\text { goldacre MJ } \\
2008 \text { et al } \\
\end{array}$ & Retrospective & England & 586525 & - & $233410: 353115$ & 55000 & - & - & - & - & - & - & - & - \\
\hline $\begin{array}{l}\text { Ganesh A et } \\
\text { al2016 }\end{array}$ & Retrospective & Canada & 319972 & $73.16 \pm 14.3$ & 158965:161007 & 46756 & - & 46756 & - & - & - & - & - & - \\
\hline $\begin{array}{l}\text { kuster GW } \\
\text { et al } 2014\end{array}$ & Prospective & Brazil & 341 & $66.8 \pm 15.7$ & $178: 163$ & 28 & - & 28 & $\sqrt{ }$ & $\sqrt{ }$ & $\sqrt{ }$ & - & $\sqrt{ }$ & $\sqrt{ }$ \\
\hline lee $\mathrm{S}$ et $\mathrm{al}$ & Retrospective & UK & 32151 & $74.6 \pm 12.52$ & $14359: 17792$ & 4926 & 4926 & - & $\sqrt{ }$ & $\sqrt{ }$ & $\sqrt{ }$ & - & - & $\sqrt{V}$ \\
\hline
\end{tabular}




(2)

Table 2: Pooled odds ratios of precipitating factors of mortality in Stroke patients

\begin{tabular}{|l|l|l|l|l|}
\hline Precipitating factors & Number of studies & Events/Total (n/N) & Pooled event rate \% (95\% CI) & Z-value \\
\hline Hypertension & 27 studies & $1,159,461 / 2,244,341$ & $61.9 \%(52.8-71.1)^{* *}$ & 13.27 \\
\hline Diabetes & 20 studies & $195,612 / 1,106,985$ & $16.6 \%(14.1-19.0)^{* *}$ & 13.30 \\
\hline Atrial Fibrillation & 18 studies & $216,097 / 1,443,642$ & $10.3 \%(7.9-12.8)^{* *}$ & 8.40 \\
\hline Hypercholesterolemia & 19 studies & $420,144 / 1,080,155$ & $20.2 \%(10.0-30.4)^{* *}$ & 3.88 \\
\hline Alcohol & 12 studies & $30,902 / 794,300$ & $21.5 \%(10.4-32.6)^{* *}$ & 3.79 \\
\hline Cigarette smoking & 21 studies & $163,130 / 1,196,417$ & $16.3 \%(13.6-19.0)^{* *}$ & 11.85 \\
\hline
\end{tabular}

${ }^{* *} \mathrm{p}<0.001$; CI- confidence interval

\section{Figures}

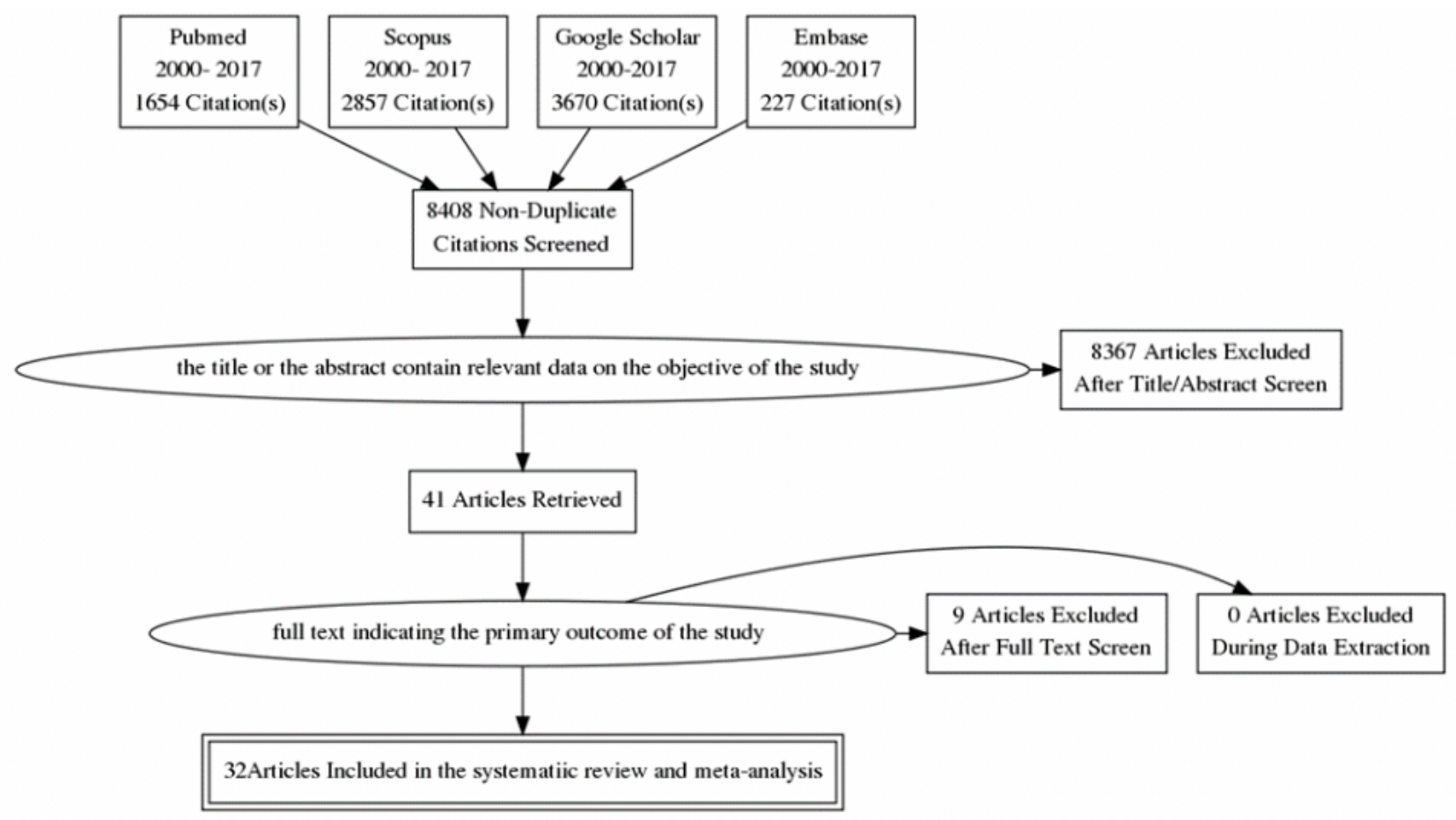

Figure 1

Flow chart indicating the selection process of studies 


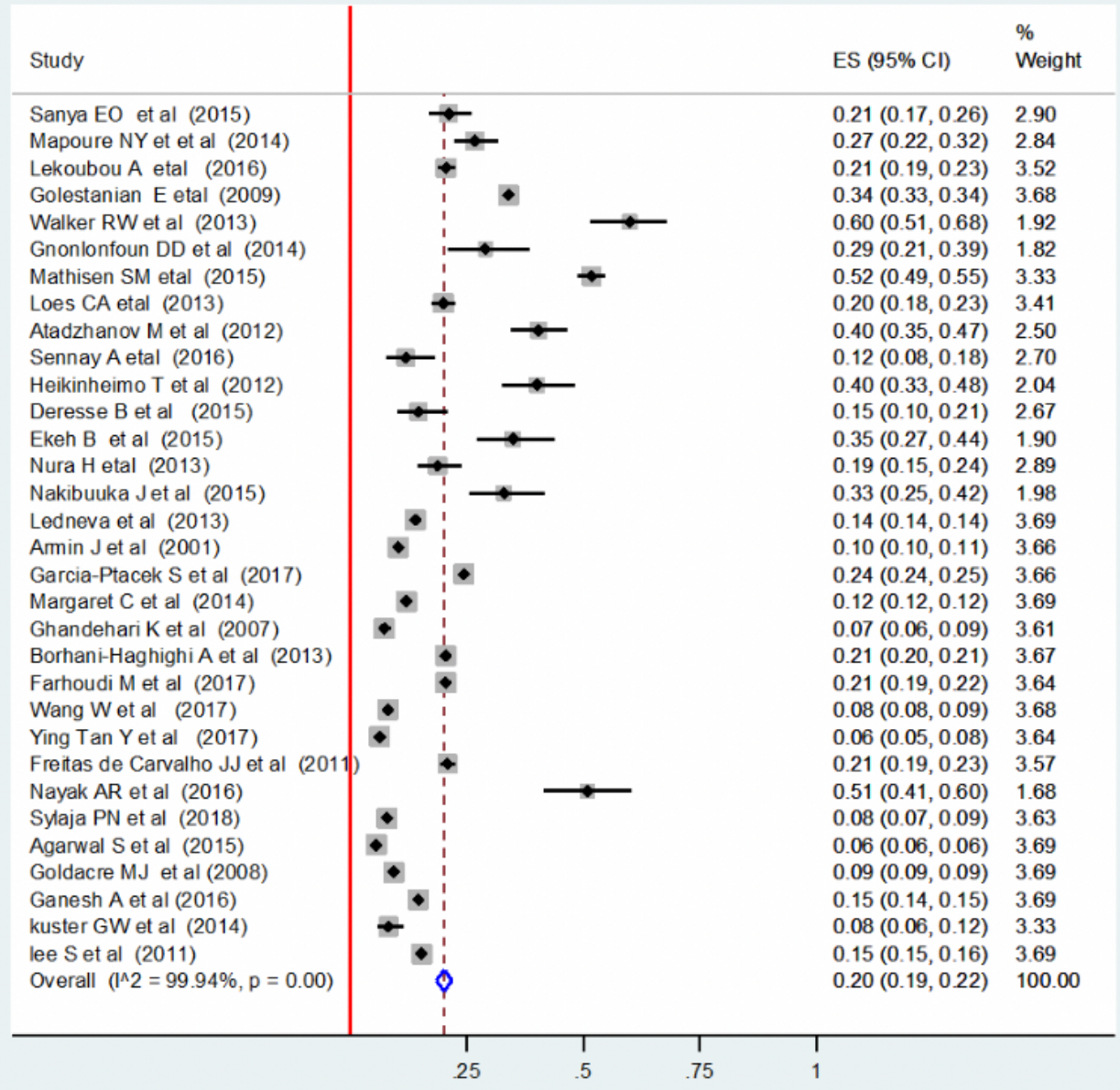

Figure 2

The overall mortality of stroke patients 


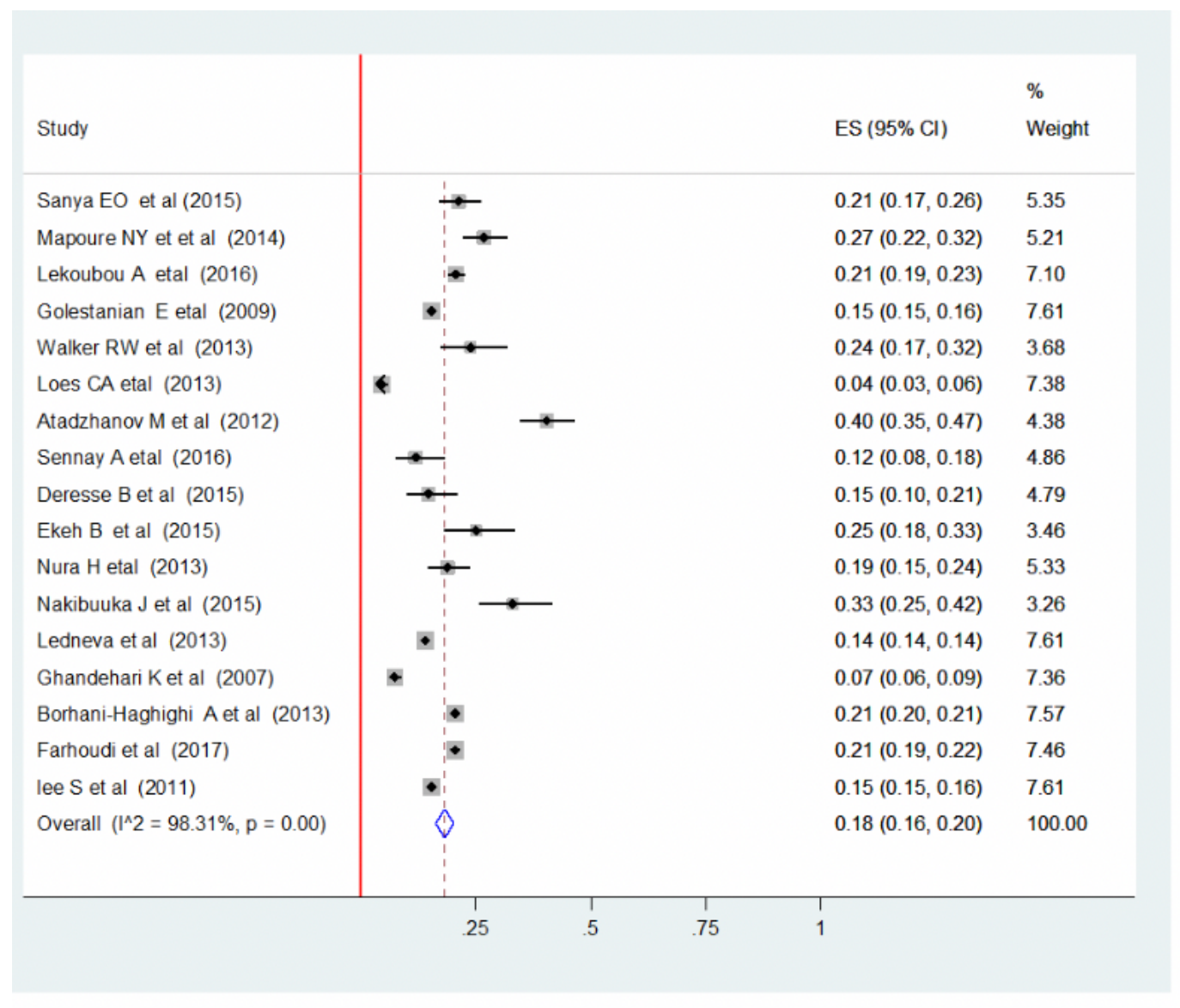

\section{Figure 3}

The thirty-day mortality of stroke patients 


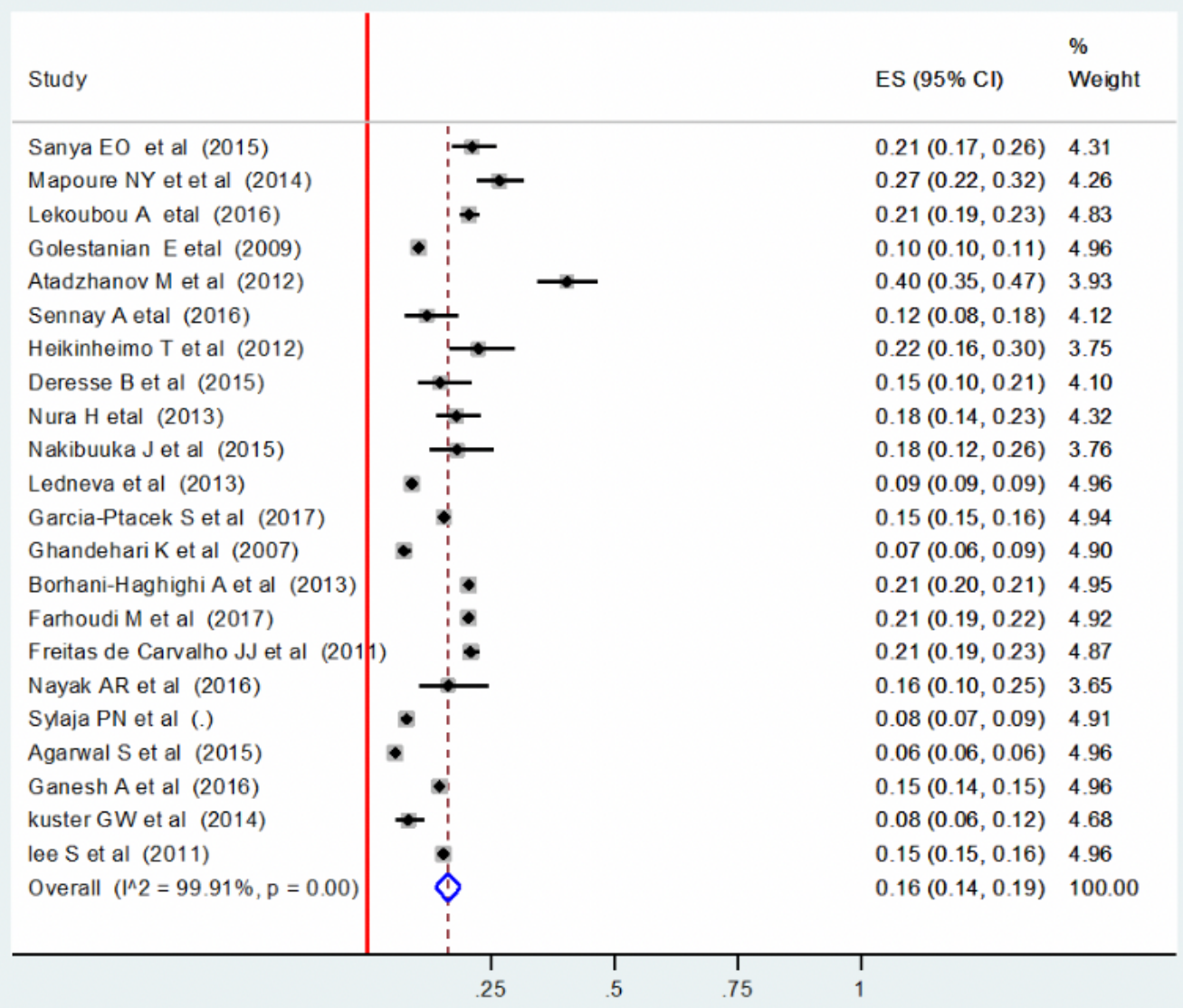

Figure 4

The In-hospital mortality of stroke patients 


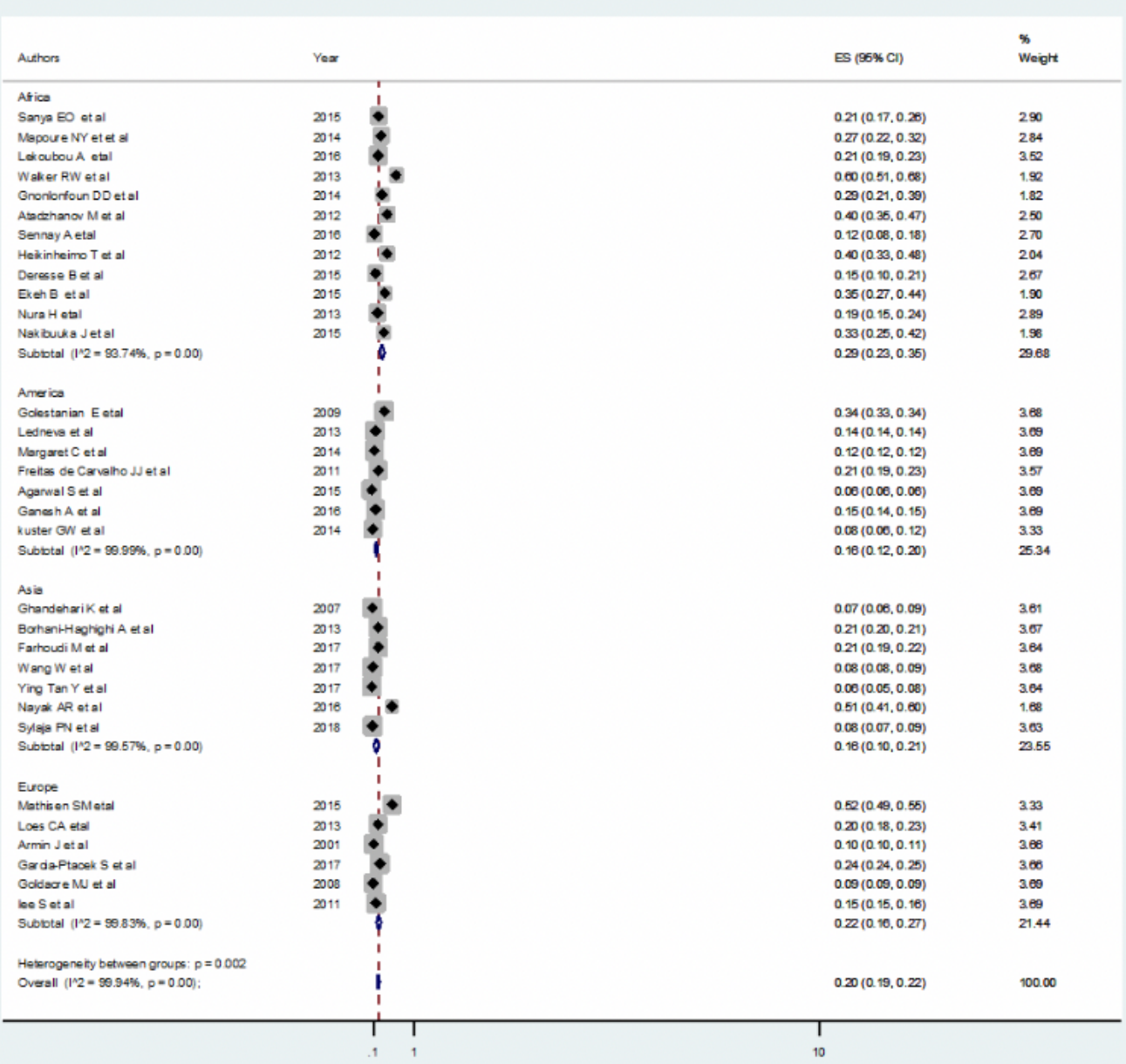

Figure 5

Mortality based on continents

\section{Supplementary Files}

This is a list of supplementary files associated with this preprint. Click to download.

- additionalfile1.docx

- additionalfile2.docx

- addtionalfile3.docx 